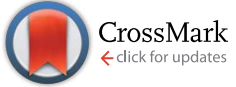

Cite this: RSC Adv., 2016, 6, 74384
Received 23rd June 2016

Accepted 26th July 2016

DOI: 10.1039/c6ra16316e

www.rsc.org/advances

\section{Comments on "Dental lessons from past to present: ultrastructure and composition of teeth from plesiosaurs, dinosaurs, extinct and recent sharks" by A. Lübke, J. Enax, K. Loza, O. Prymak, P. Gaengler, H.-O. Fabritius, D. Raabe and M. Epple, RSC Adv., 2015, 5, 61612}

\begin{abstract}
M. de Renzi, ${ }^{a}$ E. Manzanares, ${ }^{a b}$ M. D. Marin-Monfort ${ }^{c}$ and H. Botella*ab
The paper mentioned in the title suggests that several groups of extinct vertebrates used fluoroapatite as a tooth mineral in dentine and enamel when alive; its authors posit that this tooth mineralization drastically changed in all these lineages at some point during their evolution, leading to the use of hydroxyapatite as an alternative primary tooth mineral, because of hitherto unconsidered environmental changes. These conclusions are based on their finding high fluoride levels (i.e. fluoroapatite) in the dentine of fossilised shark teeth as well as in both the dentine and enamel of plesiosaurs, mosasaurs, and dinosaurs, which is in sharp contrast to recent teeth (which contain almost no fluoride in the dentin or enamel; i.e. hydroxyapatite). However, in our opinion, the authors have either obviated or underestimated a process well known to palaeontologists and archaeologists: the fluorine content of fossil teeth and bones increases with age during the course of fossilization because of the diagenetic passage of hydroxyapatite to more stable fluoroapatite. Thus, the aim of this letter is to show that the high fluoride contents found in the questioned paper are due to the diagenetic alteration of fossils, with the goal of avoiding future confusion.
\end{abstract}

\section{Introduction}

Multidisciplinary papers, such as the one mentioned in the title linking chemistry with palaeobiology, should always be welcome in specialised scientific journals. However, when a paper deals with several disparate disciplines, the authors need good advisers in each of the specific fields in order to correctly interpret the results. The absence of such consultation can lead to erroneous or nonsensical conclusions, even when the analysis is correctly carried out, as we fear has occurred in the aforementioned paper.

Lübke and colleagues used high-resolution chemical and microscopic methods to study the chemical composition and the microstructure of teeth from several vertebrate taxa, including both extant and extinct sharks, extinct marine reptiles and dinosaurs. They ...found surprising differences in chemical composition. The tooth mineral of all extinct sharks was fluoroapatite in both dentin and enameloid, in sharp contrast to recent

${ }^{a}$ Cavanilles Institute of Biodiversity and Evolutionary Biology, Universitat de València, C/Catedrático José Beltrán Martinez, 2, 46980 Paterna, Valencia, Spain

${ }^{b}$ Area of Palaeontology, Department of Botany and Geology, University of Valencia, C/ Doctor Moliner, 50, 46100,Burjassot, Valencia, Spain. E-mail: Hector.Botella@uv.es ${ }^{c}$ Department of Palaeobiology, Museo Nacional de Ciencias Naturales-CSIC, C/José Gutiérrez Abascal, 2, 28006 Madrid, Spain sharks where fluoroapatite is only found in enameloid. Unlike extinct sharks, recent sharks use hydroxyapatite as mineral in dentin. Most notably and hitherto unknown, all dinosaur and extinct marine reptile teeth contained fluoroapatite as mineral in dentin and enamel. After this the authors conclude, our results indicate a drastic change in the tooth mineralization strategy especially for terrestrial vertebrates that must have set in after the cretaceous period. Possibly, this is related to hitherto unconsidered environmental changes that caused unfavourable conditions for the use of fluoroapatite as tooth mineral. (Abstract; italic indicates statements directly quoted from the paper; bold marks are our own).

Although both the analytical methods used and the results obtained seem accurate, the conclusions reached in the paper are radically erroneous. The authors have obviated, or misunderstood, a very well established and methodically studied diagenetic process, i.e. the fluorine content of fossil teeth and bones increases with age during the course of fossilization.

\section{Fluorine in fossil teeth and bones, metabolic in origin or diagenetic?}

The mineralised tissues (bone, dentine and enamel/oid) that form the skeletal elements of vertebrates (bones, teeth, spines, dermal denticles, etc.) comprise an organic matrix and 
a mineral phase which usually consists of hydroxyapatite $\left(\mathrm{Ca}_{5}\left(\mathrm{PO}_{4}\right)_{3} \mathrm{OH}\right)$ crystallites. Exceptions to this general rule can be seen in enameloid, a thin hypermineralised layer capping the teeth of Chondrichthyes and several groups of bony fish, where the mineral phase consists of fluoroapatite $\left(\mathrm{Ca}_{5}\left(\mathrm{PO}_{4}\right)_{3} \mathrm{~F}\right) \cdot^{1-5}$ Apart from the enameloid of these taxa, where fluorine concentrations exceed $2,5 \mathrm{wt} \%{ }^{2,6-9}$ the fluorine content in mineralised tissues of modern vertebrates is consistently low (frequently less than $1 \mathrm{wt} \%$ ).

However, the amount of fluorine in fossil teeth and bones is usually considerably higher than that of contemporary ones. This fact has been known since the early nineteenth century and is one of the most studied diagenetic processes in archaeology and palaeontology. ${ }^{10}$ In these fields, the concept of diagenesis, or more specifically, fossildiagenesis, is used to cover all the chemical and mechanical changes that affect organic remains laying in a sediment or rock after their initial burial. ${ }^{11-14}$ Diagenetic modifications to fossils include processes such as compaction or distortion, mineralisation (including infilling and chemical replacement) and dissolution. ${ }^{15,16}$ Fluoride ions are present in trace amounts in most soils, groundwater, sediments and sedimentary rocks. After burial of vertebrate skeletal remains in sediments, these ions progressively replace the hydroxyl group in the mineral hydroxyapatite $;^{17,18}$ the resulting fluoroapatite present higher chemical stability than the original form..$^{17,19,20}$ Thus, buried teeth and bones accumulate fluorine over the passage of time. This was first recognized by the English chemist James Middleton in 1844, who suggested that fluorine content of fossil skeletal remains could be used as a mean of dating them..$^{21,22}$ The development of the fluorine dating method ${ }^{23,24}$ marked a turning point in the development of dating techniques, because it was the first chemical procedure to date fossil specimens, and supplemented the stratigraphic methods used up until then. ${ }^{10}$

Fluorine incorporation in fossil teeth and bones has been used extensively over the last century as a dating reference point, has solved important problems in palaeoanthropology and archaeology, and has been used to assess diagenetic processes in taphonomy. ${ }^{25}$ In fact, "fluorine dating" became very popular as a research tool when it was used with notable success to reveal one of the most famous frauds in science, the Piltdown man hoax. ${ }^{26}$ Notwithstanding, it is a relative dating method which is not universally applicable because the amount of fluorine acquired by fossils specimens does not depend exclusively on their age..$^{25,27-30}$ The rate of ion replacement is influenced by several variables controlled by sedimentological and taphonomical processes. These "diagenetic" variables synthetized by Lyman et al. ${ }^{30}$ - comprise the enclosing sediment matrix, the groundwater activity and the skeletal remains involved (including the skeletal part, its ontogenetic stage, its shape, size and density as well as the tissue represented, e.g. tooth enamel/oid, trabecular bone, dentine, etc.). ${ }^{6,30}$ Excellent comprehensive surveys (together with a definitive bibliography) on the evolution of studies on fluoridation in fossil teeth and bones, and on the use and limitations of fluorine dating have been recently published. ${ }^{10,30}$

Therefore, it is evident that finding of fluoroapatite in the dentine of fossilised shark teeth and in both the dentine and enamel/oid of plesiosaurs, mosasaurs, and dinosaurs, is not a surprising discovery (Abstract, pags. 61619, 61620) nor it is very unlikely due to a hitherto undescribed chemical pathway where hydroxyapatite recrystallized to fluoroapatite during the millions of years of diagenesis. (Pag. 61621). More than two centuries of research effort have provided satisfactory proof that the high content of fluorine generally present in fossil vertebrate remains results from secondary chemical changes occurring as part of well-understood diagenetic processes. Thus, the high amount of fluoride present in the fossil teeth studied by Lübke and colleagues must be explained from a diagenetic origin and not as originating from metabolic pathways during the animal's lifetime, as suggested by the authors.

Indeed, the dates obtained by Lübke $e t$ al. clearly corroborate a diagenetic origin when they are appropriately interpreted. For example, several previous studies have demonstrated that enamel and dentine react differently during the course of the diagenetic introduction of fluorine. Thus, bone and dentine with high permeability and small apatite crystallite size contain 2-3 times the amount of fluorine as coexisting enamel with low permeability and large crystallites. ${ }^{6}$ The values measured by Lübke and colleagues for the dentine and enamel of "dinosaur" teeth perfectly fit with this proportion (their Table 1, but please note that $P$. mauretanicus and $M$. beaugei are not dinosaurs, but rather, belong to other different groups of reptiles).

Nevertheless, Lübke et al. rule out diagenetic explanations based on two inaccurate arguments: (1) the lack of alteration in the microstructure of the fossil teeth (specifically in sharks) and (2) the presence of high fluorine content, which was similar in all the fossil teeth they studied. Another, albeit less probable reason for the presence of fluoroapatite in the dentin of all investigated teeth could be a hitherto undescribed chemical pathway where hydroxyapatite recrystallized to fluoroapatite during the millions of years of diagenesis. Given the fact that the measured fluoride content was high and similar on all extinct species despite their different age, excavation sites and diagenetic history, this appears very unlikely. Therefore, we rule out artefacts, e.g. of an intake of fluoride during fossilization, as the teeth were preserved in completely different environments and as this would not explain the pathway of fluoride inside all these fossilized teeth samples without changing the crystal morphology.../...therefore... we are convinced that fluoroapatite was present in the teeth of the extinct species when they were still alive. (Pag. 61621).

Firstly, we must pay attention to the passage from hydroxyapatite to fluoroapatite. In the former, hydroxyl groups are replaced by fluoride ions; i.e. an ion-to-ion substitution, without modification of the crystalline system: the crystals remain in the same hexagonal organisation (Fig. 1). Thus, no ultrastructural changes can be observed in this replacement ${ }^{32,33}$ and only at minute scales (50 to $25 \mathrm{~nm}$ ) can some effects be observed. ${ }^{34}$ In any case the fact that the basic ultrastructural design of the fossilized shark teeth is almost identical to that of recent sharks (pag. 61618) cannot be a valid argument for rejecting a chemical pathway where hydroxyapatite recrystallized to fluoroapatite (pag. 61621) because, as the authors correctly noted, the enameloid of current Chondrichthyes consist of fluoroapatite instead of 


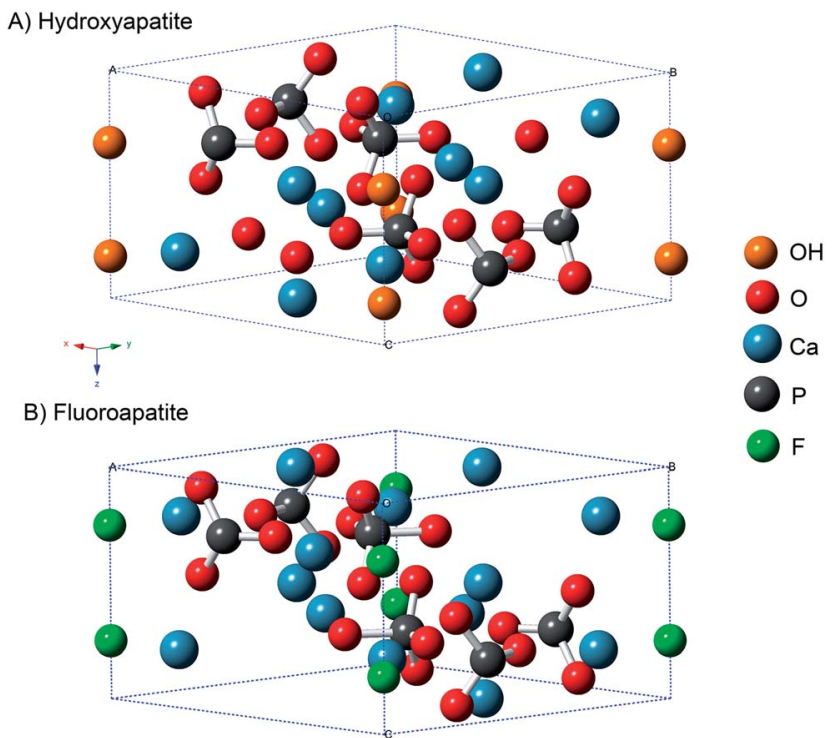

Fig. 1 Schematic representation of hydroxyapatite and fluoroapatite unit cells. Cell volumes are $528.69 \AA^{3}$ and $523.1 \AA^{3}$ respectively. Cell parameters $a=b=9.42 \AA$ and $c=6.88 \AA$ for hydroxyapatite; $a=b=$ $9.38 \AA$ and $c=6.88 \AA$ for fluoroapatite. Data and images were obtained using Crystallography Open Database. ${ }^{31}$. (COD ID hydroxyapatite: 4317043; fluoroapatite: 1011044).

hydroxyapatite. Thus, fluoroapatite was in fact the original component in this case.

Secondly, high concentrations of fluorine are generally expected to be found in fossil teeth. The fluoridation process begins at the very moment hydroxyapatite remains are enclosed in a sediment, continues after the sediments become consolidated sedimentary rocks, and finishes when palaeontologists discover the fossils in these rocks. It is well-known that fluorine reaches concentrations ranging from around 300 to more than $700 \mathrm{ppm}$ in the most common sediments (carbonate, sandstones and shales), and this ranges between 500 and 1300 ppm in sedimentary rocks. Therefore, this is not a matter of the availability of fluorine in the fossilisation environment. Fluoride gradually occupies the hydroxyl ions places until the hydroxyapatite is finally completely transformed into fluoroapatite (note that maximum complete hydroxyl-group substitution allows a theoretical maximum introduction of $3.8 \%$ fluorine). ${ }^{20,35}$ Fluorine measurements have been used in archaeology for bones and teeth less than a thousand years old and some authors have suggested that they can provide chronological resolution capable of distinguishing between buried remains separated by as little as 40 years. ${ }^{25}$ Therefore, it is expected, that fossil teeth several millions of years old (such as those studied by the authors of the contentious paper) are close to fluorine content saturation because most of their hydroxyls have already been replaced.

In fact, data obtained by Lübke and colleagues support this: in our Fig. 2 we have plotted the fluorine content in the tooth enameloid and dentine from shark species from recent to Late Cretaceous times presented in the original paper, placing the values for current species on the ordinate axis (age $=0)$. The enameloid of modern shark teeth (consisting of fluoroapatite)

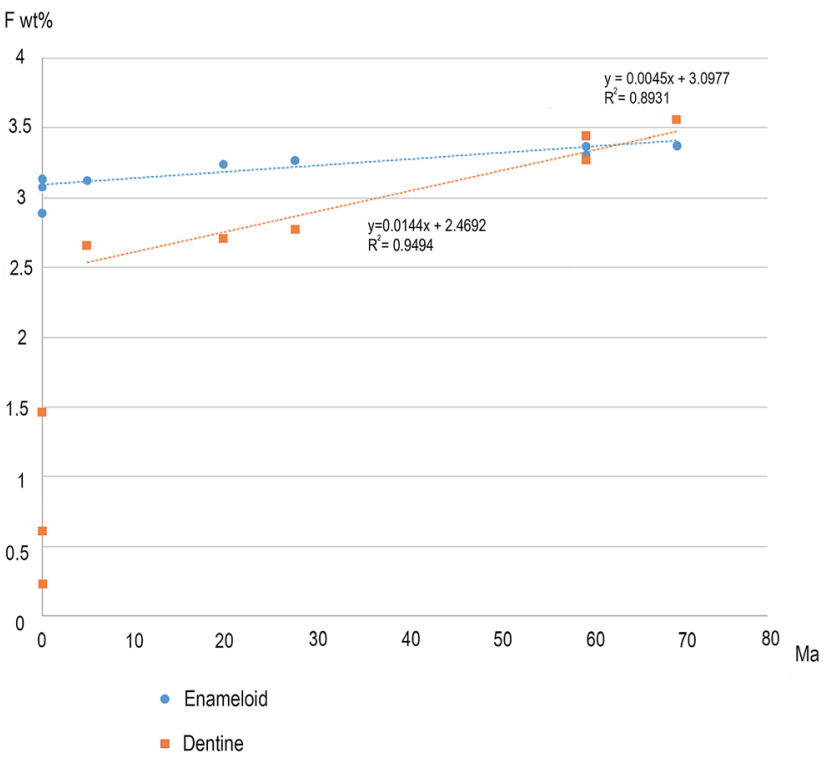

Fig. 2 Fluorine content in shark teeth analysed by Lübke et al. (2015; Table 1) ranging from recent to Late Cretaceous times. Data indicate a high correlation between fluorine contend and geological age (but see text).

have a high fluorine content (average $3.03 \mathrm{wt} \%$; s.d. $=0.13$ ) close to stoichiometric fluoroapatite levels. Values for enameloid fluorine show a moderate linear increase with geological age, ranging up to $3.38 \mathrm{wt} \%(70 \mathrm{Ma})$. The regression line $(x=$ geological age; $y=\mathrm{wt} \%)$ is $y=0.0045 x+3.0977 ; R^{2}=0.8931$. On the other hand, the fluoride content for current shark dentine is low (average $0.77 \mathrm{wt} \%$; s.d. $=0.63$ ). As we can see, fluorine content in dentine increases rapidly, reaching a concentration of $2.65 \mathrm{wt} \%$ in the younger fossil teeth studied (Pliocene, $5 \mathrm{Ma}$ ). After this, fluorine more slowly increases with the geological age, ranging from $2.65 \mathrm{wt} \%$ (5 Ma) to $3.56 \mathrm{wt} \%$ for the oldest (70 Ma). The linear regression for fossil dentine is $y=0.0142 x+$ 2472; $R^{2}=0.9515$. In both cases, the correlation coefficient is significantly different from zero, with $p<0.008$ for enameloid and $p<0.005$ for dentine (d.f. $=3$ ). Raw data for both enameloid and dentine fit their respective regression lines very well. Consequently, data from the original paper in fact shows progressive fluorine enrichment as geological time increases.

Nevertheless, it is important to note here that the high correlation between the content of fluorine ions and geologic age found in Lübke and colleagues' data is very probably due to chance because of the low number of fossil teeth considered in their study [i.e. a single tooth for Pliocene (5 Ma), Miocene (23$5.3 \mathrm{Ma}$ ), Oligocene (28 Ma) and Late Cretaceous (70 Ma); two teeth for the Paleocene times $(60 \mathrm{Ma})]$. As previously mentioned, the increase in fluorine in buried bones and teeth is not only time-dependent but is also influenced by a plethora of other variables. Thus, several studies have demonstrated that although an ascending trend in fluorine content with increasing age is usually recognizable, skeletal remains of the same age but from different sites may contain extremely variable fluorine amounts, which is attributable to different fossildiagenetic conditions. By example, fluorine concentrations exceeding the 
theoretical maximum value are found in fossil caused by if other chemical changes during diagenesis such us incorporation of calcium fluoride. ${ }^{20,35,36}$

\section{Other conceptual problems}

Sharks are cartilaginous fish, i.e. they have no bones. These chondrichthyans joined the evolution 460 million years ago. A remarkable difference to bony fish species is the fact that the mineral in their teeth is fluoroapatite, $\mathrm{Ca}_{5}\left(\mathrm{PO}_{4}\right)_{3} \mathrm{~F}$, instead of hydroxyapatite, $\mathrm{Ca}_{5}\left(\mathrm{PO}_{4}\right)_{3} \mathrm{OH}$. (Pag. 61616).

Shark teeth are made of two different tissues, i.e. enameloid and dentine. The mineral phase is fluoroapatite only in the enameloid; in the rest of the teeth it is hydroxyapatite. As in sharks, numerous species of bony fishes have fluoroapatite in their enameloid..$^{2,7,9,37}$ It is relevant to note here that several studies have demonstrated that fluorine ion incorporation into enameloid in bony fishes is related to phylogeny, not to food or environmental conditions. ${ }^{2}$

In general, the basic ultrastructural design of the fossilized shark teeth is almost identical to that of recent sharks and differs only in details such as the number and the distribution of circumferential bundles, if present. This suggests an optimized ultrastructure in shark teeth that withstood natural selection pressure without changing over time. Shark teeth represent a piscivorous dentition, and they are optimally adapted to catch the prey or to crack mussels (in the case of rays). They have no masticatory function; therefore, there was no evolutionary "pressure" to develop enamel. (Pag. 61618).

This paragraph includes several misunderstood concepts and generalisations that have led to misinterpretations. Chondrichthyan dentitions show a great diversity of trophic adaptations, which are categorised into five major groups: clutching-, tearing-, cutting- crushing- and grinding-type. ${ }^{38}$ The term piscivorous dentition is confusing, especially given that only a moderate proportion of sharks base their diets exclusively in fish. Notably, seals, dolphins and porpoises, sea birds, whales, crabs and even sea turtles can contribute a significant amount to the diet of all the recent species Lübke et al. considered. ${ }^{39,40}$ In the same sense, the inferred diets for the fossil taxa studied include dinosaurs, mosasaurs and turtles for Squalicorax pristodontus ${ }^{41}$; or whales, dolphins, other large marine mammals and giant see turtles $^{42}$ for the Megalodon and Palaeogene species.

However, hard preys with resistant exoskeletons are the basis of the diet of some recent chondrichthyans; i.e., they are durophagous animals, with grinding-type dentitions such as those found in Myliobatiformes, some guitarfishes and several Mesozoic hybodont sharks. ${ }^{42,43}$ These taxa present complex prey-processing mechanisms (i.e. "masticatory" function) even though they lack tooth enamel. ${ }^{44}$ Note that, in contrast, an enamel layer is present in the teeth of reptiles and amphibians, which typically lack the elaborated mastication mechanisms characteristic of mammals.

In fact, the ultrastructure of chondrichthyan tooth enameloid has undergone substantial changes over time and these have been related to the evolutionary history of the group. Thus, the multicuspidate teeth of the earliest (Palaeozoic) chondrichthyans, which adapted exclusively for a grasping and swallowing predation, possess only a homogeneous layer of single crystallite enameloid (SCE) lacking any microstructural differentiation. ${ }^{45,46} \mathrm{~A}$ two-layered enameloid, with a compact outer SCE layer and a bundled inner layer, appears in the crushing teeth of some Mesozoic hybodontiforms ${ }^{47,48}$ and it is present in several fossil living batoids. ${ }^{49}$ In contrast, the teeth of all non-batoid neoselachians, i.e., modern sharks, show a triple layered enameloid, consisting of an inner layer of tangledbundled enameloid, an intermediate layer of parallel-bundled enameloid, and the outermost shiny-layered enameloid with crystallites not arranged in bundles. ${ }^{50}$ This microstructural differentiation has been linked to the emergence of the different trophic strategies mentioned above. ${ }^{45,49,51}$

Our results imply that a greater group not only of sea-living but also of land-living vertebrates has used fluoroapatite as tooth mineral. At some point during the evolution, the environmental circumstances may have changed and prevented the incorporation of fluoride into the apatite lattice of teeth. (From conclusions, but also see the Abstract)//the fact that teeth from such very distantly related animal groups used the same fluoroapatite mineral composition for both enamel (oid) and dentin strongly suggests that during their lifetime in prehistoric times, the conditions, i.e. the abundance of fluoride, were more favourable than in recent times. (Pag. 61621).

The authors of this previously cited text have an erroneous point of view on the evolutionary process when they say that such disparate vertebrate groups as sharks, dinosaurs or mosasaurs simultaneously enriched their teeth in fluorine. Metabolism evolves independently from one phylogeny to another, and this evolution depends first on suitable gene batteries (whether present or not in every lineage), and second on the environmental action, which differ in each case (natural selection). Thus, these two features are independent. A simultaneous change in metabolism in these different lineages, due to an unverified decrease in fluorine in both marine and terrestrial environments, as proposed by these authors is almost impossible.

Additionally, and as a side note, we do not recommend use of the term 'prehistoric' to generally designate extinct animals, as Lübkle et al. do, because this term is only reserved for mankind and its cultural activities in a time period before that covered by written history.

This mineral [fluoroapatite] dissolves in contact with acids (such as acidic fruits) below a pH of about 5. Contrary to hydroxyapatite as in human and mammalian teeth, it releases hydrofluoric acid (HF) which is a highly toxic compound. This will be rapidly diluted and removed for sea-living organisms such as sharks, but will remain in the mouth for land-living dinosaurs. (Pag. 61621).

Thus, according to this line of thoughts, this original fluoroapatite would have had deleterious effects to the terrestrial vertebrates. However, as odontologists know very well, fluorine compliments are very useful: fluorine prevents dental cavities, and above all, demineralisation of dental enamel by supplying stabilising fluoride to human hydroxyapatite enamel. ${ }^{52,53}$ These facts are also well known from other surveys. ${ }^{32}$ Lübke and colleagues contradict the conclusions of dental health specialists because human 
beings eat acidic fruits as well as other animals but do not become intoxicated by $\mathrm{HF}$ or other products from acidic reactions with fluoroapatite. Moreover, the passive input of fluorine throughout fossilisation processes reinforces the stability of teeth, which thus become one of the most durable elements, and are therefore relatively easily preserved. ${ }^{32}$

\section{Acknowledgements}

This work has been founded by the Spanish Government. Ministerio de Economía y Competitividad. Research Project CGL2014-52662-P. We wish to thank Dr Javier Sanz, Dr Guillermo Mínguez and Dr Eugenio Coronado at the Institute for Molecular Science (ICMOL), Valencia, Spain.

\section{References}

1 H. A. Lowenstam and S. Weiner, On biomineralization, Oxford University Press, 1989.

2 K. Prostak, P. Seifert and Z. Skobe, J. Dent. Res., 1991, 70, 1266-1271.

3 K. S. Prostak and P. Seifert, Arch. Oral Biol., 1993, 38, 1031-1044. 4 M. Wakita, Kaibogaku Zasshi, 1993, 68, 399-409.

5 C. Chen, Z. Wang, M. Saito, T. Tohei, Y. Takano and Y. Ikuhara, Angew. Chem., Int. Ed., 2014, 53, 1543-1547.

6 R. B. Parker, J. Murphy and H. Toots, Archaeometry, 1974, 16, 98-102.

7 R. Z. LeGeros and S. Suga, Calcif. Tissue Int., 1980, 32, 169174.

8 S. Suga and H. Nakahara, Mechanisms and Phylogeny of Mineralization in Biological Systems: Biomineralization'90, Springer Science \& Business Media, 2012.

9 S. Suga, Y. Taki and M. Ogawa, J. Dent. Res., 1992, 71, 13161325.

10 M. R. Goodrum and C. Olson, Br. J. Hist. Sci., 2009, 42, 95114.

11 A. H. Müller, Lehrbuch der Paläozoologie. 1. Allgemeine Grundlagen, Fischer, 1963.

12 A. Müller, Treatise on Invertebrate Paleontology (A): Introduction, ed. R. A. Robison and C. Teichert, Geological Society of America, Boulder, Colorado, and University of Kansas, Lawrence, Kansas, 1979.

13 A. Seilacher, Europal, 1995, 8, 23-25.

14 S. R. Fernández López and Y. Fernández Jalvo, Current topics on Taphonomy and Fossilization, Ajuntament de València, 2002.

15 S. R. Fernández López, M. H. P. Henriques and L. V. Duarte, Abh. Geol. Bundesanst., 2002, 57, 423-430.

16 C. E. Brett and J. R. Thomka, Fossils and Fossilisation, eLS, 2013.

17 A. Haddy and A. Hanson, Archaeometry, 1982, 24, 37-44.

18 R. Berger and R. Protsch, Scientific Dating Methods, Kluwer Academic, Dordrecht, 1991, pp. 251-270.

19 A. R. Hagen, Calcif. Tissue Res., 1973, 13, 259-270.

20 G. A. Wagner, Age determination of young rocks and artifacts: physical and chemical clocks in quaternary geology and archaeology, Springer Science \& Business Media, 1998.
21 J. Middleton, J. Proc. Geol. Soc. Lond., 1844, 4, 431-433.

22 J. Middleton, Q. J. Geol. Soc. London, 1845, 1, 214-216.

23 K. Oakley, Adv. Sci., 1948, 4, 336.

24 M.-A. Carnot, Recherches sur la Composition générale et la Teneur en Fluor des os Modernes et des os fossiles des différents ages, Ch. Dunod, 1893.

25 M. R. Schurr and D. A. Gregory, Am. Antiq., 2002, 281-299.

26 K. P. Oakley and C. R. Hoskins, Nature, 1950, 165, 379-382.

27 S. Cole, S. Afr. Archaeol. Bull., 1954, 9, 18-24.

28 S. F. Cook and H. Ezra-Cohn, SW. J. Anthropol., 1959, 276-290.

29 H. Toots and R. B. Parker, Rocky Mt. Geol., 1979, 18, 69-70.

30 R. L. Lyman, C. N. Rosania and M. T. Boulanger, J. Field Archaeol., 2012, 37, 226-237.

31 S. Gražulis, A. Daškevič, A. Merkys, D. Chateigner, L. Lutterotti, M. Quirós, N. R. Serebryanaya, P. Moeck, R. T. Downs and A. LeBail, Nucleic Acids Res., 2012, 40(Database issue), D420-D427, Accessed July 2016.

32 J. Lucas and L. E. Prévôt, Taphonomy: releasing the data locked in the fossil record, Plenum Press, 1991.

33 B. Wopenka and J. D. Pasteris, Mater. Sci. Eng., C, 2005, 25, 131-143.

34 Y. Dauphin, P. Massard and C. Quantin, Palaeogeogr., Palaeoclimatol., Palaeoecol., 2008, 266, 134-141.

35 H. Y. Göksu and D. Regulla, Scientific dating methods, Springer Science \& Business Media, 1991.

36 K. P. Oakley, Relative dating of the fossil hominids of Europe, British Museum (Natural History), 1980.

37 A. Carr, A. Kemp, I. Tibbetts, R. Truss and J. Drennan, J. Microsc., 2006, 221, 8-16.

$38 \mathrm{H}$. Cappetta and H. Schultze, Handbook of Palaeoichthyology $E$, Verlag Dr Friedrich Pfeil, 2012, vol. 3.

39 The IUCN Red List of Threatened Species 2009:e. T39341A10207466, DOI: 10.2305/IUCN.UK.20092.RLTS.T39341A10207466.en, Accessed June 2016.

40 FishBase, http://www.fishbase.org, Accessed June 2016.

41 D. R. Schwimmer, J. Stewart and G. D. Williams, Palaios, 1997, 71-83.

42 H. Cappetta, Handbook of paleoichthyology, Verlag Dr Friedrich Pfeil, 1987, vol. 3, pp. 1-193.

43 M. N. Dean, J. J. Bizzarro and A. P. Summers, Integr. Comp. Biol., 2007, 47, 70-81.

44 M. N. Dean, C. D. Wilga and A. P. Summers, Biol. Lett., 2005, 1, 357-361.

45 J. A. Gillis and P. C. Donoghue, J. Morphol., 2007, 268, 33-49. 46 H. Botella, J. Vertebr. Paleontol., 2006, 26, 1002-1003.

47 G. Cuny, O. Rieppel and P. Sander, J. Linn. Soc. London, Zool., 2001, 133, 285-301.

48 C. Pla, A. Márquez-Aliaga and H. Botella, J. Vertebr. Paleontol., 2013, 33, 770-785.

49 E. Manzanares, D. Rasskin-Gutman and H. Botella, J. Linn. Soc. London, Zool., 2016, 177, 621-632.

50 W. E. Reif, Zool. Scr., 1974, 2, 231-250.

51 D. Thies and W. Reif, Neues Jahrb. Geol. Palaeontol., Abh., 1985, 169, 333-361.

52 A. I. Ismail and H. Hasson, J. Am. Dent. Assoc., 2008, 139, 1457-1468.

53 I. V. Miñana, Acta Pediatr. Esp., 2010, 68, 185. 